\title{
The Relationship between Sustained Attention and PTSD Symptoms in Chinese Earthquake Orphans
}

\author{
Yan Wang ${ }^{2}$, Xingli Zhang ${ }^{*}$, Jiannong Shi ${ }^{*}$ \\ ${ }^{1}$ Institute of Psychology, Chinese Academy of Science, Beijing, China \\ ${ }^{2}$ Ming Zheng Judicial Expertise Center, Jilin, China \\ Email: *zhangxl@psych.ac.cn, *shijn@psych.ac.cn
}

How to cite this paper: Wang, Y., Zhang, X.L. and Shi, J.N. (2017) The Relationship between Sustained Attention and PTSD Symptoms in Chinese Earthquake Orphans. Open Access Library Journal, 4: e3729. https://doi.org/10.4236/oalib.1103729

Received: June 9, 2017

Accepted: July 23, 2017

Published: July 26, 2017

Copyright ( $\odot 2017$ by authors and Open Access Library Inc.

This work is licensed under the Creative Commons Attribution International License (CC BY 4.0).

http://creativecommons.org/licenses/by/4.0/

\section{(c) (i) Open Access}

\begin{abstract}
The authors examined sustained attention performance and PTSD symptoms in a sample of 281 orphans and non-orphans who experienced the Sichuan Earthquake in China. They hypothesized that the orphans had a higher possibility to risk for PTSD than non-orphans, and the former also might even tend to be more impulsive, allergic which might affect their basic cognitive skillattention. The findings showed evidence of cognitive developmental stages, from vigilance to numbness and avoidance, in the continuous performance test (CPT) task by including pre-earthquake orphans. The post-earthquake orphans were still in a high level of vigilance and performed well in the CPT task when compared with the pre-earthquake orphans. The non-orphans with high possibility to risk for PTSD were the most concentrated and least impulsive. Given the potentially mutual relationship between sustained attention and posttraumatic stress disorder, careful consideration must be given to the treatment of traumatized children who present with PTSD symptoms. In accordance with practice guidelines, a duplex informant, duplex measure approach in the decision of educational plans for these children is strongly recommended.
\end{abstract}

\section{Subject Areas \\ Psychology \\ Keywords \\ Pre-Earthquake Orphans, Post-Earthquake Orphans, Sustained Attention, PTSD Symptoms}

\section{Introduction}

On May 12, 2008, Sichuan huge earthquake, which has been deemed one of the 
worst natural disasters to hit China, devastated Sichuan causing overwhelming physical, life, emotional, and economic losses. There are about 630 orphans left behind after the earthquake [1]. United Nations International Children's Emergency Fund (UNICEF) [2] has identified parentally bereaved children as "unprotected", and at high risk for engagement in hazardous forms of labor with the potential for serious injury, forced sexual exploitation, loss of educational opportunities, malnutrition, and disease. Despite the enormity of this problem, there is a paucity of empirical studies documenting the short or longer-term psychological, functional and life-trajectory consequences for this vulnerable population [3].

Stoppelbein and Greening [4] found that parentally bereaved children reported significantly more symptoms of pathological state than the disaster and non-trauma control groups, such as re-experience, avoiding and high-arousing, which are clinical manifestations of post-traumatic stress disorders (PTSD). Persistent separation from parents immediately after a natural disaster (such as a hurricane or flood), along with the loss of the child's home, pets, toys, and friends also predicts PTSD in children [5] [6] [7]. PTSD is defined as a delayed and long-term sustained individual mental disorder caused by sudden, threatening or catastrophic life events [8]. Included in the re-experience cluster are intrusive thoughts, distressing nightmares, and dissociative flashbacks, in which memory for the traumatic event repeatedly intrudes into awareness. Paradoxically, psychogenic amnesia, an inability to remember important aspects of the trauma, is included in the avoidance cluster. In the third cluster, there are symptoms indicative of disturbed attention and hyperarousal, including poor concentration, hypervigilance and enhanced startle response [9].

Besides increasing risk for PTSD, many children who experience severe trauma also experience symptoms of attention deficit/hyperactivity disorder (ADHD), which is marked by a combination of extreme inattention, impulsivity, and hyperactivity [8]. Attention plays an important role in the development of children's basic cognitive skills. Sustained attention (sometimes also referred to as persistent attention) describes a fundamental component of attention characterized by the subject's readiness to detect rarely and unpredictably occurring signals over prolonged periods of time [10]. It is a key factor for many perceptual and cognitive activities to be completed successfully and efficiently. As early as in 1956, Rosvold and his colleagues [11] proposed: as a measurement of sustained attention, CPT (continuous performance test) was very sensitive for the brain damage and cognitive dysfunction. At present, $\mathrm{CPT}$ is the most widely used paradigm to measure sustained visual attention [12]. Generally, the CPT task requires participants to sustain their attention and alertness to low-frequency sensory signals, minimize distractibility to irrelevant stimuli over time. In clinical applications, $\mathrm{CPT}$ is also very sensitive for the response inhibition of the impulsion, often used in studies such as attention deficit, schizophrenia, and depression [13] [14] [15]. In current study, CPT was employed to evaluate the children's sustained attention performance in two symptoms, inattention and impulsivity/ 
hyperactivity.

Because of overlap in the hyperactive-inattentive symptoms of sustained attention and the arousal symptoms of PTSD, some studies have found that PTSD had been associated with subjective complaints of poor concentration and memory [16] [17] [18] [19]. Vasterling et al. [20] found that Gulf War (GW) veterans diagnosed with PTSD showed more false errors in the CPT task compared with GW veterans without mental disorders. Therefore, the study found that the PTSD symptoms have a relative relationship with impairments in sustained attention. Vasterling et al. [21] repeated the results of the study in follow-up study fundamentally. Koso and Hansen [22] examined attention functions of 20 PTSD veterans from Bosnian with the SART task (Sustained Attention to Response Task). The results showed that, compared with the control group, veterans with PTSD was not inferior in the reaction speed in SART task, but the omission errors and false errors were significantly increased. Brandes et al. [23] investigated the association between cognitive impairment and early PTSD symptoms of the survivors within 10 days right after the traumatic event with the DF and DB tasks (Forward and Backward Digit Span Tasks), and found survivors with high levels of PTSD symptoms showed impaired attention. Husain et al. [24] supported that PTSD symptoms would mediate the relationship between trauma exposure and attention problems in a sample of 791 Sarajevan children exposed to the Bosnian war. Sims [25] found that children with clinical levels of hyperarousal and avoidance symptoms performed worse on tasks of sustained attention when compared to children without clinical levels of symptoms.

Our main concern was sustained attention performance in Sichuan preearthquake and post-earthquake orphans and non-orphaned children who had high or low possibility to risk for PTSD symptoms. The pre-earthquake orphans had lost their parents before Sichuan earthquake, and they could be a contrast group which would predict the future of earthquake orphans when they might experience some huge events. The current study was also to examine the prevalence of PTSD in the orphans and non-orphans. How was their sustained attention influenced by the earthquake? In this article we significantly investigated these children's psychological problems such as allergies and impulse which tended to be reflected in CPT task due to an earthquake and/or loss of their parents. These will help us to better guide and assist the earthquake children to re-enter into everyday life and normal learning courses as quickly as possible. It's also very meaningful if we understand the relationship between sustained attention and PTSD symptoms. Based on this information, psychological and educational aid and intervention will be more practical for these children.

\section{Methods}

\subsection{Subjects}

Participants were children from Shandong Experimental School, where relocated and educated the children who lost their parent or family in the huge earth- 
quake. The school consists of an elementary school and a junior middle school. All children were from grade 3 to grade 8 . At the beginning of the test, the main instructor informed students of test contents, methods, processes, and time. Students who didn't want to take the test could quit. In the test process, those who did not wish to continue might also exit. Finally, 281 children (146 boys and 135 girls $)$ aged 8 to $16(M=12.7$ years, $S D=1.72)$ finished the tests. According to information provided by the school, children were divided into three groups including pre-earthquake orphans and post-earthquake orphans and non-orphans. Pre-earthquake orphans consisted of 54 girls $(M=12.7, S D=1.74)$ and 71 boys $(M=12.9, S D=1.82)$. Post-earthquake orphans consisted of 37 girls $(M=12.5$, $S D=1.84)$ and 50 boys $(M=12.5, S D=1.67)$. Non-orphans consisted of 44 girls $(M=12.5, S D=1.68)$ and 25 boys $(M=13.2, S D=1.21)$.

\subsection{Measures}

Continuous Performance Test CPT: The experimental material of CPT task was the number of $1-9$, which was the type of $1 \rightarrow 9$ [26] [27]. 540 numbers from 1 to 9 appeared randomly on the center of the screen at the rate of one per second, and digit presenting time was $200 \mathrm{~ms}$, while controlling the ratio of 1 followed by 9 to be 0.1 (this could ensure the emergence of target at a low-frequency in line with the requirements of CPT task). Participants were asked to respond to 9 when it followed after 1 by pressing the space bar correctly and quickly. Test parameters in Table 1 were recorded and calculated to evaluate the CPT performance.

Children's Revised Impact of Event Scale CRIES [28]: the CRIES was a newly developed 13-item scale, adapted from the IES-8 [29]. It was widely used for PTSD screening with good reliability and validity, and easily operated and suitable for detecting a large sample of children who were at risk after disaster [30]. Chinese version of CRIES was translated and revised to relate to the earthquake into Chinese by Zhu et al. [31]. It included 4 items measuring intrusion, 4 items

Table 1. CPT parameters.

\begin{tabular}{|c|c|c|}
\hline Parameter & Definition & Remark \\
\hline $\begin{array}{l}\text { The average reaction } \\
\text { time (ms) }\end{array}$ & $\begin{array}{c}\text { The average response time of } \\
\text { correct responses }\end{array}$ & Processing speed \\
\hline Hit rate $(\%)$ & $\begin{array}{l}\text { The number of targets detected/ } \\
\text { the number of targets } \times 100 \%\end{array}$ & Hit: correct response, concentration \\
\hline False alarm rate $(\%)$ & $\begin{array}{c}\text { The number of responses to } \\
\text { non-target stimuli/the number of } \\
\text { non-target stimuli } \times 100 \%\end{array}$ & False alarm: impulsivity \\
\hline Sensitivity $d^{\prime}$ & $\mathrm{z}$ (Hit) - z(False) & $\begin{array}{l}\text { Perceptual sensitivity (the ability to } \\
\text { discriminate between the target and } \\
\text { non-target stimuli) }\end{array}$ \\
\hline Response bias $\beta$ & $\begin{array}{c}\text { Vertical coordinates of } \\
\text { Hit/Vertical coordinates of False }\end{array}$ & $\begin{array}{l}\text { Impulsivity and conservation (the } \\
\text { subject's criterion or "willingness" to } \\
\text { report detection of a signal) }\end{array}$ \\
\hline
\end{tabular}


measuring avoidance and 5 new items, corresponding to DSM-IV Criterion D symptoms, measuring arousal. Individual items were rated according to the frequency of their occurrence during the past week (None $=0$, Rarely $=1$, Sometimes $=3$, and Often $=5$ with no reversed items) and in relation to Sichuan earthquake written at the top of the scale. The total score indicated severity of post-traumatic stress reactions and ranged from 0 to 65 . The CRIES in this study showed good internal consistency for the Intrusion (Chronbach's alpha $=0.82$ ), Avoidance (0.70), Arousal (0.73), and Full Scale (0.87).

\subsection{Procedures}

In CPT task which used VC language to prepare the experimental program, stimulate material displayed on 17-inch CRT with black words and white background, and the computer's refresh rate was $75 \mathrm{HZ}$. Before entering the formal experiment, the main instructor explained guidance and rules, and led the students to do some oral practice. The whole formal test lasted 12 minutes. The main instructors were assigned to psychological graduate students, with consistent instruction.

The CRIES was carried out by groups, and the main instructors were also assigned to psychological graduate students, with uniform survey methodology and guidance. One class as a unit, students independently filled in and returned the questionnaires at the scene.

\section{Results}

\subsection{PTSD Symptoms}

PTSD symptoms of three groups were in Table 2. The multivariate analysis of variance (MANOVA) comparing scores on intrusion factor revealed significant differences between groups $(F(2,280)=3.54, P=0.030)$. Then, using LSD method to do post hoc test, the results showed that on avoidance factor postearthquake orphans scored significantly higher $(P=0.047)$ and the pre- earthquake orphans scored marginal significantly higher than non-orphans $(P=$ 0.056); on intrusion factor the pre-earthquake orphans scored significantly lower than post-earthquake orphans $(P=0.009)$. Based on the cutoff (IES score (intrusion + avoidance) $\geq 17$ or $<17$ ), $46.0 \%$ post-earthquake orphans had a high possibility to risk for PTSD, while the percent of the pre-earthquake orphans $40.0 \%$ and the percent of the non-orphans $30.4 \%$. By $\chi^{2}$ test, significant more post-

Table 2. PTSD symptoms of pre-earthquake and post-earthquake orphans and non-orphans and differences between groups.

\begin{tabular}{cccccc}
\hline Factors & $\begin{array}{c}\text { Pre-earthquake } \\
\text { orphans }\end{array}$ & $\begin{array}{c}\text { Post-earthquake } \\
\text { orphans }\end{array}$ & Non-orphans & $F$ & $P$ \\
\hline Intrusion & $7.01 \pm 5.32$ & $8.99 \pm 5.78$ & $7.55 \pm 4.93$ & 3.54 & 0.030 \\
Avoidance & $8.02 \pm 5.27$ & $8.18 \pm 4.99$ & $6.57 \pm 4.64$ & 2.40 & 0.093 \\
Arousal & $7.38 \pm 5.99$ & $7.29 \pm 5.56$ & $7.07 \pm 5.44$ & 0.07 & 0.936 \\
\hline
\end{tabular}


Table 3. CPT parameters of pre-earthquake and post-earthquake orphans and non-orphans and differences in CPT performance between those who have high and low possibility to risk for PTSD of each group.

\begin{tabular}{ccccccc}
\hline Group & $\begin{array}{c}\text { PTSD2 } \\
\text { symptoms } \\
\text { (cutoff 17) }\end{array}$ & $\begin{array}{c}\text { Reaction time } \\
(\mathrm{ms})\end{array}$ & $\begin{array}{c}\text { Hit rate } \\
(\%)\end{array}$ & $\begin{array}{c}\text { False alarm } \\
\text { rate }(\%)\end{array}$ & $\begin{array}{c}\text { Sensitivity } \\
d^{\prime}\end{array}$ & $\begin{array}{c}\text { Response } \\
\text { bias } \beta\end{array}$ \\
\hline & High & $402.0 \pm 46.95$ & $76.5 \pm 22.84$ & $5.0 \pm 5.76$ & $1.50 \pm 1.08$ & $1.28 \pm 1.22$ \\
$\begin{array}{c}\text { Pre-earthquake } \\
\text { orphans }\end{array}$ & Low & $389.2 \pm 63.59$ & $79.3 \pm 22.67$ & $4.4 \pm 4.39$ & $1.37 \pm 0.91$ & $0.95 \pm 0.59$ \\
& $F$ & 1.49 & 0.42 & 0.37 & 0.58 & 3.97 \\
& $P$ & 0.225 & 0.516 & 0.545 & 0.448 & 0.048 \\
Post-earthquak & Low & $401.7 \pm 80.49$ & $82.0 \pm 21.28$ & $4.0 \pm 4.87$ & $1.42 \pm 0.79$ & $1.35 \pm 2.75$ \\
e orphans & $F$ & 0.97 & 0.09 & 0.02 & 0.34 & 0.37 \\
& $P$ & 0.328 & 0.767 & 0.887 & 0.561 & 0.545 \\
& High & $378.5 \pm 57.23$ & $86.2 \pm 18.13$ & $2.1 \pm 2.64$ & $1.15 \pm 0.67$ & $0.93 \pm 0.27$ \\
& Low & $381.8 \pm 56.95$ & $76.9 \pm 27.35$ & $4.9 \pm 5.24$ & $1.66 \pm 1.05$ & $1.13 \pm 1.67$ \\
& $F$ & 0.05 & 2.04 & 5.18 & 4.17 & 0.31 \\
\hline Non-orphans & $P$ & 0.825 & 0.158 & 0.026 & 0.045 & 0.577 \\
\hline
\end{tabular}

earthquake orphans had a high possibility to risk for PTSD than non-orphans $\left(\chi^{2}(1)=3.904, P=0.048\right)$. Based on the cutoff (IES Total score $\geq 30$ or $<30$ ), the percent of post-earthquake orphans who had a high possibility to risk for PTSD was $34.5 \%$, while the percent of the pre-earthquake orphans $26.4 \%$ and the percent of the non-orphans $23.2 \%$. By $\chi^{2}$ test, there were no significant differences between groups.

\subsection{CPT Performance}

CPT performances of three groups were in Table 3. Setting the group and high or low possibility to risk for PTSD as fixed variables, the two-factor MANOVA comparing scores revealed the interaction in sensitivity were marginal significant different $(F(1,280)=3.00, P=0.051)$ when the cutoff of PTSD was 30 . Then the comparisons between each two groups were analyzed. Figure 1 illustrated the results of false alarm rate and sensitivity of three groups in CPT task. The results of MANOVA of each two groups demonstrated that the interaction in false alarm rate between non-orphans and pre-earthquake orphans was significant different $(F(1,193)=4.54, P=0.034)$ when the cutoff of PTSD was 17 . Also the interaction in false alarm rate between non-orphans and post-earthquake orphans was marginal significant different $(F(1,155)=3.33, P=0.070)$. Moreover, the interaction in sensitivity between pre-earthquake orphans and post-earthquake orphans was marginal significant different $(F(1,211)=3.71, P$ $=0.055)$ when the cutoff of PTSD was 30 . Also the interaction in sensitivity between pre-earthquake orphans and non-orphans was significant different ( $F$ $(1,193)=4.28, P=0.040)$. The results also displayed that the main effect 

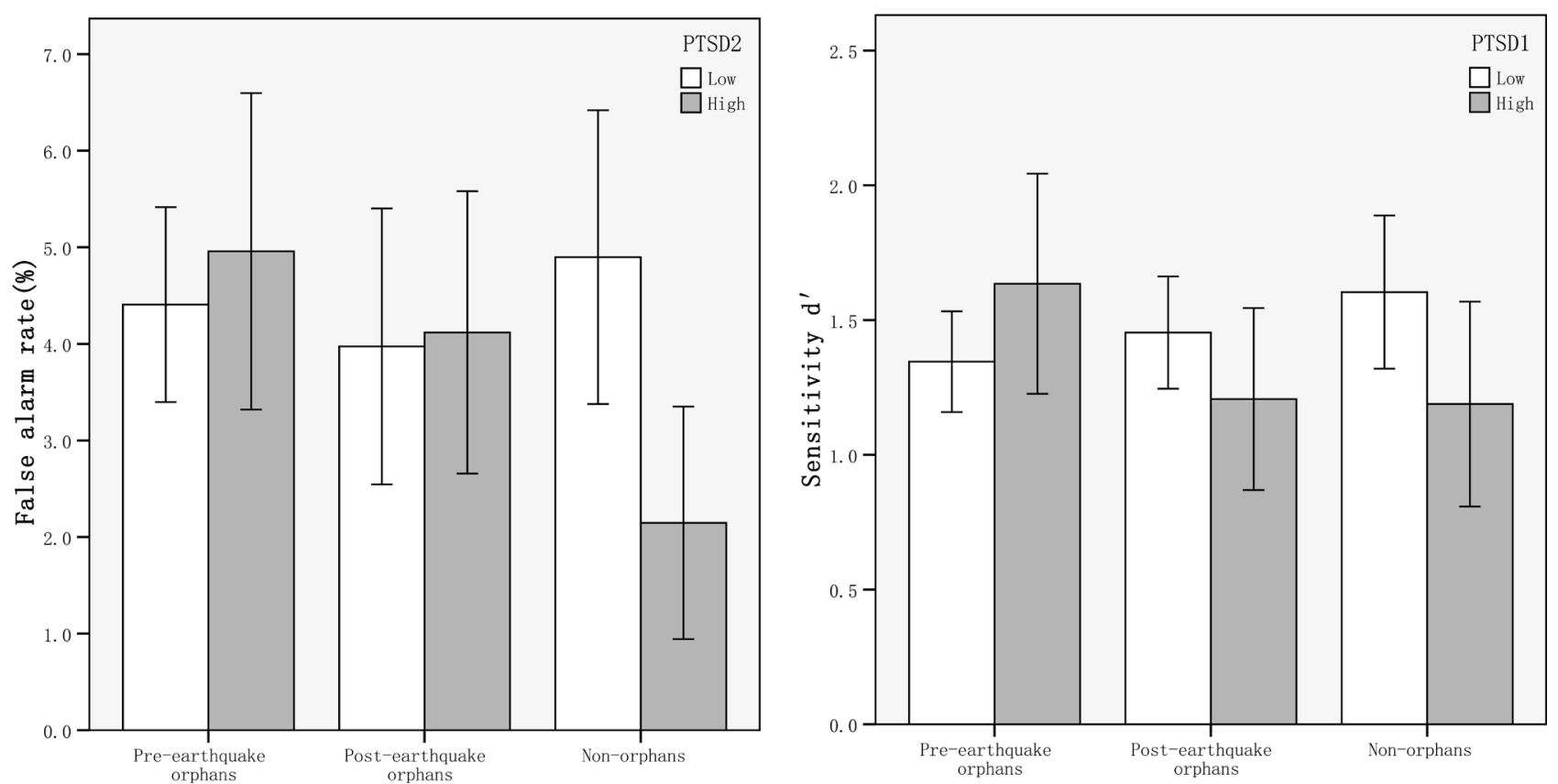

Note: the cutoff of PTSD1 (total score) is 30, the cutoff of PTSD2 (intrusion + avoidance) is 17.

Figure 1. The results of false alarm rate and sensitivity of three groups in CPT task.

of PTSD symptoms in sensitivity between non-orphans and post-earthquake orphans were significant different $(F(1,155)=4.16, P=0.043)$ when PTSD symptoms was grouped by both 30 and 17 .

When PTSD was grouped by 17, the results of MANOVA of each group (see Table 3) showed that for the pre-earthquake orphans, the response bias of those who had a high possibility to risk for PTSD was significant larger than those who had a low possibility $(F(1,124)=3.97, P=0.048)$; For the non-orphans group, the false alarm rate and sensitivity of those who had a high possibility to risk for PTSD was significant smaller than those who had a low possibility $(F(1,68)=$ 5.18, $P=0.026 ; F(1,68)=4.17, P=0.045)$; For the post-earthquake orphans group, the results was found no significant differences between those who had high and low possibility to risk for PTSD.

\subsection{CPT Performance in Relation to PTSD Symptoms}

Table 4 displayed correlation analysis between three groups' CPT performance and PTSD symptoms. For the pre-earthquake orphans, the intrusion factor of CRIES had significant positive correlation with the reaction time and sensitivity in the CPT task, and the arousing factor had significant positive correlation with sensitivity and response bias. The intrusion factor also had marginal significant positive correlation with false alarm rate and response bias, and arousing factor also had a marginal significant positive correlation with false alarm rate. For the post-earthquake orphans, the avoiding factor had marginal significant negative correlation with reaction time and response bias in the CPT task. For the nonorphans, the intrusion factor had significant negative correlation with false alarm rate and sensitivity. 
Table 4. Correlation analysis between CPT performance and PTSD symptoms of three groups.

\begin{tabular}{cccccccc}
\hline Group & $\begin{array}{c}\text { Control } \\
\text { Variable }\end{array}$ & Variable & $\begin{array}{c}\text { Reaction } \\
\text { time }\end{array}$ & Hit rate & $\begin{array}{c}\text { False alarm } \\
\text { rate }\end{array}$ & $\begin{array}{c}\text { Sensitivity } \\
d^{\prime}\end{array}$ & $\begin{array}{c}\text { Response } \\
\text { bias } \beta\end{array}$ \\
\hline $\begin{array}{c}\text { Pre-earthquake } \\
\text { orphans }\end{array}$ & Age & $\begin{array}{c}\text { Intrusion } \\
\text { factor }\end{array}$ & $0.20^{*}$ & -0.13 & $0.16^{+}$ & $0.19^{*}$ & $0.17^{+}$ \\
& Avoidance \\
factor & 0.13 & -0.02 & 0.01 & 0.08 & 0.09 \\
Post-earthquake \\
orphans
\end{tabular}

Note: ${ }^{+} P<0.09{ }^{*} P<0.05^{* *} P<0.01$.

\section{Discussion}

This study showed that the pre-earthquake and post-earthquake orphans had more avoidance response than the non-orphans group. When the cutoff of IES- 8 was 17 , significant more post-earthquake orphans had a high possibility to risk for PTSD. The results supported that orphans had a greater likelihood of suffering from PTSD [4] [7]. Children reported the highest levels of social support from their parents [6]. After experiencing a great catastrophic event, orphans who had lost support and safely comfort from parents easily had more psychological problems, such as suffering from PTSD and so on. However, Goenjian et al. [3] found that loss of both parents and, to a lesser degree, loss of a father was not a significant risk factor for PTSD. Possibly different with current study carried out half of a year after the earthquake, orphans had changed their PTSD symptoms 61/2 years after the 1988 Spitak earthquake. Chen et al. [32] investigated PTSD symptoms in children one year and two years after Taiwan 9.21 earthquake and found that PTSD symptoms had different performances at different stages, and the overall situation was toward a positive direction over time, with a weakening trend but not much decline in avoidance and re-experience. On the other hand, from comparison results between the post-earthquake and preearthquake orphans, the latter already had significant less intrusion experience than the former, and there was no significant difference between pre-earthquake orphans and non-orphans. Moreover, in avoidance response there was no difference between post-earthquake orphans and pre-earthquake orphans. Taken into account pre-earthquake orphans who had become orphans before 
the earthquake, they had gone through a period of mental struggle, and became less sensitive to the traumatic events and emotional paralysis, so took the reaction of avoidance as self-defense. Accordingly, the post-earthquake orphans were still in the early stages of reaction to traumatic events, and they performed more intrusion experience, and also adopted evasive response as self-defense.

Compared the results of the CPT task between those who had high and low possibility to risk for PTSD, for the pre-earthquake orphans, those who had a high possibility to risk for PTSD are more inclined to impulse since they tended to a significant greater extent of response bias than those with a low possibility. For the non-orphans, children who had a high possibility to risk for PTSD had significantly lower false alarm rate and sensitivity than those who had a low possibility, which was in contrast to the results of previous studies [20] [22] [33]. The reason might be the veterans received the test long time after the trauma and in the current study children were still in much higher vigilance state only six months after the earthquake. Moreover, these results from adults were not easily spread and comparable to the study of children. From the results of comparison between two groups in sensitivity and false alarm rate, the non-orphans with a high possibility to risk for PTSD showed a better concentration level than the pre-earthquake orphans. For the post-earthquake orphans, although there were no significant differences between orphans with high and low possibility to risk for PTSD, the results reflected the former's reaction time than the latter's was relatively shorter and response bias even less. There was a trend the postearthquake orphans with high possibility to risk for PTSD were less impulsive and more concentrated than those with low possibility. From the comparisons between post-earthquake and pre-earthquake orphans in sensitivity, and between the former and non-orphans in false alarm rate, the results displayed that the pre-earthquake orphans with high possibility to risk for PTSD were more inattention than post-earthquake orphans with high possibility, and the latter were more impulsive than non-orphans with high possibility. To sum up, unlike the pre-earthquake orphans whose vigilance became weak after a long time, the post-earthquake orphans who went through a huge natural disaster 6 months ago, lost the most pro-parents, a larger psychological shock, were still in a state of nervous tension and therefore their concentration (alert) levels were relatively high, and show relatively less impulsivity. The non-orphans with high possibility to risk for PTSD were the most concentrated and least impulsive.

This study also did correlation analysis of three groups between CPT performance and PTSD symptoms. For the pre-earthquake orphans, those who experienced more intrusion and high arousing performance were more impulsive and sensitive in CPT task. For the post-earthquake orphans, those who showed more avoidance to the earthquake event completed the CPT tasks with a quicker reaction speed and higher level of concentration (alert). For the non-orphans, those who experienced more intrusion were less impulsive. Contrary to the non-orphans and post-earthquake orphans, pre-earthquake orphans had positive relationship between PTSD symptoms and the level of impulsivity, which 
was consistent with the results of previous research [23] [24]. This point was also consistent with the results discussed above. Probably the reason is that postearthquake orphans and non-orphans still needed a long time to adjust to the seismic events, and six months after the earthquake (test time) they were still in a sensitive and alert state, especially for those with a high possibility to risk for PTSD.

These results might prompt us, at the beginning stage, the earthquake PTSD orphans who were impacted by earthquake and had been hit hard in psychology, were more sensitive and alert. First of all, under the premise of ensuring the correct rate they performed a faster reaction speed; then further on, until transferred to judge impulsively, they had higher response bias and false alarm rate and became impulsive, lack of patience. This method of cognitive-behavioral experiment to detect the earthquake orphans' cognitive behavior-attention and post-traumatic stress disorder, it might reveal the earthquake PTSD orphans' developmental stage of cognitive behavior, and provided important theoretical support and guidance to establish effective prevention and treatment of children with PTSD. However, there were still two limitations in this study. Firstly, the pre-earthquake orphans hadn't been controlled completely on their demography materials considering to the sample size. They might lose their parents for many different reasons and for different lasting periods. Secondly, only CRIES was used to measure PTSD symptoms and authors had to make any conclusion very carefully. In the future the follow-up study will help to further reveal the PTSD earthquake orphans' developmental stage of cognitive behavior. It was worth noting that by including pretrauma measures. Parslow and Jorm [34] concluded that the poorer performance on some neurocognitive tests (word recall, digit span, coding speed, and vocabulary) might be a vulnerability factor for developing symptoms of PTSD, not only an outcome of PTSD symptoms. The relationship between PTSD and sustain attention problems would be a valuable and important issue, and including pretrauma measures would be crucial. On the other hand, Marsac et al. [35] explored the association between children's coping, coping assistance and acute stress reactions following an injury. They found child coping was associated with parent and peer coping assistance strategies, and suggested that children's acute stress reactions may influence their selection of coping and coping assistance strategies. Park, Nam and Bae [36] examined the association between psychological trauma, parenting attitude, and ADHD symptoms in Korean children and suggested a parenting influence on the association between exposure to psychological trauma and the severity of ADHD symptoms in children. Further studies about children's recovery from trauma are warranted.

\section{Conclusions and Contribution}

The orphans before the earthquake experienced another major traumatic event. There were different situations. After the trauma, the good ones were more resistant, less impulsive and those who grew badly after trauma caused greater 
reactions, and became more sensitive. This suggests that, for earthquake orphans who experienced traumatic events in the first time, to help them recover to the level of mental health better and faster, will help them be better in the face of a traumatic event that may occur later in their life.

First, previous studies have paid more attention to the self-esteem, self-awareness, personality and mental health status of the orphans after the earthquake. However, there are few researches on the orphans after the earthquake in the perspective of cognitive. Our study is the first to investigate the relationship between sustained attention and PTSD symptoms of the orphans in Wenchuan Earthquake, which is a useful complement to the study of Chinese earthquake children. Second, the findings show evidence of cognitive developmental stages, from vigilance to numbness and avoidance, in the continuous performance test (CPT) task by including pre-earthquake orphans. These findings will remind our social assistance system to pay more attention to orphans in traumatic events.

\section{Acknowledgements}

This research was supported by The Key Project of Knowledge Innovation Engineering of Chinese Academy of Sciences: Emergency Research of Psychological Aid for People in Wenchuan Earthquake (No. KKCX1-YW-05) "Psychological Need and Aid for Orphans and Disabled Children in Sichuan Earthquake". We greatly appreciate the support of all the children from Rizhao Experimental School in Shandong Province.

\section{References}

[1] Department of Civil Affairs of Sichuan Province (2009) Only 12 of 630 Wenchuan Earthquake Orphans Have Been Adopted. (In Chinese) http://www.chinanews.com.cn/gn/news/2009/05-11/1685072.shtml

[2] United Nations International Children's Emergency Fund (UNICEF) (2006) Invisible Children: The State of the World's Children.

[3] Goenjian, A.K., Walling, D., Steinberg, A.M., Roussos, A., Goenjian, H.A. and Pynoos, R.S. (2009) Depression and PTSD Symptoms among Bereaved Adolescents 6 $1 \frac{1}{2}$ Years after the 1988 Spitak Earthquake. Journal of Affective Disorders, 112, 81 84. https://doi.org/10.1016/j.jad.2008.04.006

[4] Stoppelbein, L. and Greening, L. (2000) Posttraumatic Stress Symptoms in Parentally Bereaved Children and Adolescents. Journal of the American Academy of Child and Adolescent Psychiatry, 39, 1112-1119. https://doi.org/10.1097/00004583-200009000-00010

[5] Pynoos, R.S. and Nader, K. (1993) Issues in the Treatment of Posttraumatic Stress Disorder in Children and Adolescents. In: Wilson, J.P. and Raphael, B., Eds., International Handbook of Traumatic Stress Syndromes, Plenum Press, New York, 535-549. https://doi.org/10.1007/978-1-4615-2820-3_46

[6] Vernberg, E.M., La Greca, A.M., Silverman, W.K. and Prinstein, M.J. (1996) Prediction of Posttraumatic Stress Symptoms in Children after Hurricane Andrew. Journal of Abnormal Psychology, 105, 237-248.

https://doi.org/10.1037/0021-843X.105.2.237

[7] Norris, F.H., Friedman, M.J., Watson, P.J., Byrne, C.M., Diaz, E. and Kaniasty, K. 
(2002) 60,000 Disaster Victims Speak: Part I. An Empirical Review of the Empirical Literature, 1981-2001. Psychiatry, 65, 207-239. https://doi.org/10.1521/psyc.65.3.207.20173

[8] American Psychiatric Association (APA) (2000) Diagnostic and Statistical Manual of Mental Disorders. 4th Edition, American Psychiatric Publishing, Inc., Washington DC.

[9] Golier, J., Yehuda, R., Cornblatf, B., Harvey, P., Gerber, D. and Levengood, R. (1997) Sustained Attention in Combat-Related Posttraumatic Stress Disorder. Integrative Physiological and Behavioral Science, 32, 52-61. https://doi.org/10.1007/BF02688613

[10] Sarter, M., Givens, B. and Bruno, J.P. (2001) The Cognitive Neuroscience of Sustained Attention: Where Top-Down Meets Bottom-Up. Brain Research Reviews, 35, 146-160. https://doi.org/10.1016/S0165-0173(01)00044-3

[11] Rosvold, H.E., Mirsky, A.F., Sarason, I., Bransome, E.D. and Beck, L.H. (1956) A Continuous Performance Test of Brain Damage. Journal of Consulting Psychology, 20, 343-350.

[12] Riccio, C.A., Waldrop, J.J.M., Reynolds, C.R. and Lowe, P. (2001) Effects of Stimulants on the Continuous Performance Test (CPT): Implications for CPT Use and Interpretation. The Journal of Neuropsychiatry and Clinical Neurosciences, 13, 326 335. https://doi.org/10.1176/jnp.13.3.326

[13] Ballard, J.C. (1996) Computerized Assessment of Sustained Attention: Interactive Effects of Task Demand, Noise, and Anxiety. Journal of Clinical and Experimental Neuropsychology, 18, 864-882. https://doi.org/10.1080/01688639608408308

[14] Van Leeuwen, T.H., Steinhausen, H.C., Overtoom, C.C.E., Pascual Marqui, R.D., van't Klooster, B., Rothenberger, A., Sergeant, J.A. and Brandeis, D. (1998) The Continuous Performance Test Revisited with Neuroelectric Mapping: Impaired Orienting in Children with Attention Deficits. Behavioural Brain Research, 94, 97-110.

[15] Zillessena, K.E., Scheuerpfluga, P., Fallgatterb, A.J., Strikc, W.K. and Warnke, A. (2001) Changes of the Brain Electrical Fields during the Continuous Performance Test in Attention-Deficit Hyperactivity Disorder-Boys Depending on Methylphenidate Medication. Clinical Neurophysiology, 112, 1166-1173.

[16] Klonoff, H., McDougall, G., Clark, C., Kramer, P. and Horgan, J. (1976) The Neuropsychological, Psychiatric, and Physical Effects of Prolonged and Severe Stress: 30 Years Later. Journal of Nervous and Mental Disease, 63, 246-252. https://doi.org/10.1097/00005053-197610000-00003

[17] Goldfield, A.E., Mollica, R.F., Pesavento, B.H. and Faraone, S.V. (1988) The Physical and Psychological Effects of Torture: Symptomatology and Diagnosis. Journal of the American Medical Association, 259, 2725-2729. https://doi.org/10.1001/jama.1988.03720180051032

[18] Weiner, H. (1992) Perturbing the Organism: The Biology of Stressful Experience. University of Chicago Press, Chicago.

[19] Uddo, M., Vasterling, J.J., Brailey, K. and Sutker, P.B. (1993) Memory and Attention in Combat-Related Post-Traumatic Stress Disorder (PTSD). Journal of Psychopathology and Behavioral Assessment, 15, 43-52. https://doi.org/10.1007/BF00964322

[20] Vasterling, J.J., Brailey, K., Constans, J.I. and Sutker, P.B. (1998) Attention and Memory Dysfunction in Posttraumatic Stress Disorder. Neuropsychology, 12, 125 133. https://doi.org/10.1037/0894-4105.12.1.125 
[21] Vasterling, J.J., Duke, L.M., Brailey, K., Constans, J.I., Allain, A.N. and Stuker, P.B. (2002) Attention, Learning, and Memory Performances and Intellectual Resources in Vietnam Veterans: PTSD and No Disorder Comparisons. Neuropsychology, 16, 5-14. https://doi.org/10.1037/0894-4105.16.1.5

[22] Koso, M. and Hansen, S. (2006) Executive Function and Memory in Posttraumatic Stress Disorder: A Study of Bosnian War Veterans. European Psychiatry, 21, 167173.

[23] Brandes, D., Ben-Schacharb, G., Gilboa, A., Bonne, O., Freedman, S. and Shalev, A.Y. (2002) PTSD Symptoms and Cognitive Performance in Recent Trauma Survivors. Psychiatry Research, 110, 231-238.

[24] Husain, S.A., Allwood, M.A. and Bell, D.J. (2008) The Relationship between PTSD Symptoms and Attention Problems in Children Exposed to the Bosnian War. Journal of Emotional and Behavioral Disorders, 16, 52-62. https://doi.org/10.1177/1063426607310847

[25] Sims, A.J.Z. (2015) Examining the Relationship between Posttraumatic Stress Disorder Symptoms and Attention Deficits in Children. Doctorial Dissertation, Tulane University, ProQuest Dissertations Publishing, Ann Arbor.

[26] Lin, C.C., Hsiao, C.K. and Chen, W.J. (1999) Development of Sustained Attention Assessed Using the Continuous Performance Test among Children 6-15 Years of Age. Journal of Abnormal Child Psychology, 27, 403-412. https://doi.org/10.1023/A:1021932119311

[27] Aylward, G.P., Brager, P. and Harper, D.C. (2002) Relations between Visual and Auditory Continuous Performance Tests in a Clinical Population: A Descriptive Study. Developmental Neuropsychology, 21, 285-303. https://doi.org/10.1207/S15326942DN2103_5

[28] Smith, P., Perrin, S., Dyregrov, A. and Yule, W. (2003) Principal Components Analysis of the Impact of Event Scale with Children in War. Personality and Individual Differences, 34, 315-322.

[29] Dyregrov, A. and Yule, W. (1995) Screening Measures: The Development of the UNICEFF Screening Battery. 4th European Conference on Traumatic Stress, Paris, May 1995.

[30] Perrin, S., Meiser-Stedman, R. and Smith, P. (2005) The Children's Revised Impact of Event Scale (CRIES): Validity as a Screening Instrument for PTSD. Behavioural and Cognitive Psychotherapy, 33, 487-498. https://doi.org/10.1017/S1352465805002419

[31] Zhu, Z.H., Huang, F., Wang, W.Z., Zhang, J.X., Ji, Y. and Zhang, K. (2009) The Psychometric Properties of Children's Impact of Event Scale Administered via Mobile Phone. 3rd International Conference on Bioinformatics and Biomedical Engineering, 11-13 June 2009, 1-3.

[32] Chen, S.H., Lin, Y.H., Tseng, H.M. and Wu, Y.C. (2002) Posttraumatic Stress Reactions in Children and Adolescents One Year after the 1999 Taiwan Chi-Chi Earthquake. Journal of the Chinese Institute of Engineers, 25, 597-608. https://doi.org/10.1080/02533839.2002.9670734

[33] Gilbertson, M.W., Gurvits, T.V., Lasko, N.B. and Pitman, R.K. (1997) Neuropsychological Assessment of Vietnam Combat Veterans with and without PTSD. Annals of the New York Academy of Sciences, 821, 476-479. https://doi.org/10.1111/j.1749-6632.1997.tb48309.x

[34] Parslow, R.A. and Jorm, A.F. (2007) Pretrauma and Posttrauma Neurocognitive Functioning and PTSD Symptoms in a Community Sample of Young Adults. The American Journal of Psychiatry, 164, 509-515. 
https://doi.org/10.1176/ajp.2007.164.3.509

[35] Marsac, M.L., Donlon, K.A., Hildenbrand, A.K., Winston, F.K. and Kassamadams, N. (2014) Understanding Recovery in Children Following Traffic-Related Injuries: Exploring Acute Traumatic Stress Reactions, Child Coping, and Coping Assistance. Clinical Child Psychology and Psychiatry, 19, 233-243.

https://doi.org/10.1177/1359104513487000

[36] Park, S., Nam, Y.Y. and Bae, J.H. (2015) The Relationship between Psychological Trauma, Parenting Attitude and Attention-Deficit/Hyperactivity Disorder Symptoms in Korean Children. Austin Journal of Psychiatry and Behavioral Sciences, 2 , 1034 .

Submit or recommend next manuscript to OALib Journal and we will provide best service for you:

- Publication frequency: Monthly

- 9 subject areas of science, technology and medicine

- Fair and rigorous peer-review system

- Fast publication process

- Article promotion in various social networking sites (LinkedIn, Facebook, Twitter, etc.)

- Maximum dissemination of your research work

Submit Your Paper Online: Click Here to Submit

Or Contact service@oalib.com 